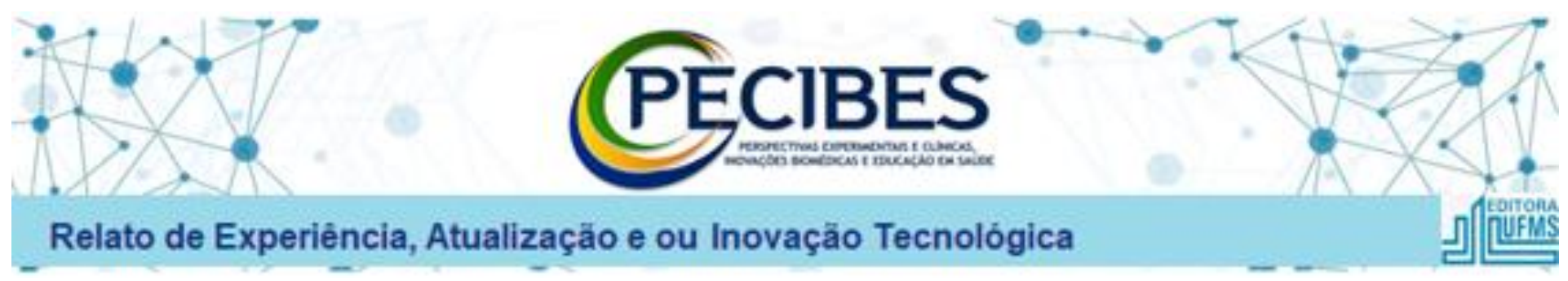

\title{
Síndrome de Guillain-Barré: Relato de Experiência
}

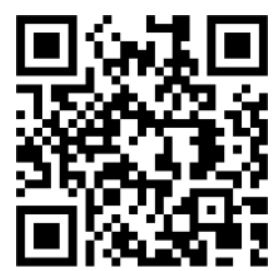

http://www.seer.ufms.br/in dex.php/pecibes/index

\section{*Autor \\ correspondente:}

Stephanie Grazielly Rodrigues Mercado, Universidade Federal de Mato Grosso do Sul- UFMS.

E-mail do autor: stephanie.mercado@uf ms.br

Palavras-chave:

Fisioterapia. SGB. Doença Autoimune.

\section{Key-words: Physical} Therapy.

SGB.autoimmune

disease
Guillain-Barré Syndrome: Experience Report

Stephanie Grazielly Rodrigues Mercado ${ }^{1}$, Evandro Gonzalez Tarnhovi² ${ }^{2}$ Juliana Teixeira de Almeida $^{3}$, Rafaela Melo dos Santos ${ }^{4}$.

${ }^{1}$ Discente da Universidade Federal de Mato Grosso do Sul -UFMS.

${ }^{2}$ Docente do Curso de Fisioterapia da Universidade Federal de Mato Grosso do SulUFMS.

${ }^{3}$ Universidade Federal de Mato Grosso do Sul -UFMS.

${ }^{4}$ Discente da Universidade Federal de Mato Grosso do Sul -UFMS.

Resumo

Este relato de experiência trata-se da descrição de caso clínico vivenciado por acadêmicos/estagiários em fase final de graduação do curso de fisioterapia na Universidade Federal de Mato Grosso do Sul, contando suas perspectivas e sentimentos frente ao atendimento no território de neurofuncional adulto II, com o intuito de demonstrar as vivências e o aprendizado durante o período de cinco anos de estudo, tendo a oportunidade de colocar em prática todos os ensinamentos adquiridos até o presente momento. A metodologia aplicada foi baseada na ficha de avaliação neurofuncional. Como resultados apresentados a evolução do paciente frente a uma doença autoimune que quando não tratada pode levar a morte.

\section{Abstract}

This experience report is about the description of a clinical case experienced by students/interns in the final phase of graduation from the physical therapy course at the Federal University of Mato Grosso do Sul, telling their perspectives and feelings regarding the care in the adult neurofunctional territory II, in order to demonstrate the experiences and learning during the five-year study period, having the opportunity to put into practice all the lessons learned so far. The methodology applied was based on the neurofunctional evaluation form. As results presented the evolution of the patient facing an autoimmune disease that when untreated can lead to death. 


\section{Introdução}

Os pesquisadores Georges Guillain, J. e A. Strohi, fizeram a primeira descrição em 1916, de uma doença com sintomatologias composta por perda de reflexos e paralisia aguda, observados em soldados do exército francês, que posteriormente foi homenageada com o nome de síndrome de Guillain-Barré (SGB) (MALTA,2020).

A SGB, por ser uma doença autoimune polirradiculoneurite, sendo aspecto de risco sua paralisia de refluxo ascendente flácida, quando não tratada que pode causar insuficiência respiratória e até mesmo a morte. Com o avanço dos estudos, com o diagnóstico precoce permite intervenções que revertem o quadro de SGB, através de tratamentos desenvolvidos (AIBENDEA, 2020).

Atualmente, a SGB é a maior responsável nas ocorrências de paralisia flácida generalizada em todo o mundo. A sua incidência é de $1-4$ casos a cada 100.000 habitantes, predominante entre 20 e 40 anos de idade. Sabese hoje, que seu caráter autoimune, compromete especialmente a mielina da porção proximal dos nervos periféricos, com ataques agudos ou subagudos (BRASIL, 2018).

Estima-se que entre a SGB, $60 \%$ a $70 \%$ dos pacientes apresentam previamente, 1 a 3 semanas antes, alguma doença aguda precedente, com maior frequência a infecção por Campilobacter jejuni (32\%). Assim como por outras infecções virais, tais como influenza, vírus da imunodeficiência humana (HIV) e hepatite (vírus tipo A, B e C). Alguns eventos raros estariam associados às intervenção cirúrgica, imunização e gravidez (BRASIL, 2018).

A desmielinização de nervos motores causada pela SGB, manifesta-se na perda de força muscular de membros inferiores (MMII), assim como comprometimento de nervos cranianos e diminuição de reflexos tendinosos profundos. Está associada a perda da função motora $e$ consequentemente da atrofia muscular, comumente sofre de déficit de equilíbrio dinâmico e estático. Considerando, a carência do sistema proprioceptivo ao receber informações tanto dos receptores articulares e musculares, que guiam segundo esses estímulos para posicionamento espacial do corpo e suas extremidades, comprometendo comandos de velocidade e amplitude do movimento (BOHRER,2015).

Além das intervenções médicas, esses deficit locomotores causados pela doença devem ser considerados, a atuação da fisioterapia torna-se indispensável nesse processo de reabilitação. Atuando na reeducação da musculatura estriada esquelética, na melhora da força muscular, prevenindo as deformidades osteomioarticulares resultantes do longo período de imobilismo, no ganho de equilíbrio, na promoção da funcionalidade e no retorno às atividades da vida diária (BOHRER,2015).

\section{Material e Métodos}

Trata- se de um relato de experiência, do tipo descritivo, de uma abordagem qualitativa, realizado por discentes do curso de fisioterapia da Universidade Federal de Mato Grosso do Sul, do qual está vinculada a prática de estágio território II, denominado neurofuncional adulto, com o propósito de avaliar e analisar as condições de saúde da população no contexto individual, familiar, domiciliar e laboral; planejar e executar ações educativas, de prevenção e promoção à saúde e de tratamento fisioterapêutico em conformidade com as necessidades individuais e coletivas de saúde da população; elaborar o diagnóstico cinesiológico funcional plano de tratamento fisioterapêutico; acompanhar e registrar a evolução do tratamento fisioterapêutico.O público alvo então foram pessoas com disfunções neurológicas e consequentemente locomotora. $\mathrm{O}$ estudo foi realizado na cidade de Campo Grande/MS, na Clínica Escola Integrada (CEI) da Universidade Federal de Mato Grosso do Sul/UFMS, no período de Agosto a Setembro de 2021 .

\subsection{Relato de experiência}

A inspiração do relato experiência foi decorrente há outras vivências do estágio, no qual observou uma melhora significativa referente aos atendimentos realizado pelos estagiários do curso de fisioterapia, com a supervisão de profissionais qualificados e responsáveis pelo território, a ideia surgiu a partir de discussões de casos referente a cada atendimento que era realizado na CEI.

A experiência da clínica prática é de suma relevância, devido o acompanhamento que aproxima o estudante e proporciona a melhora dos pacientes conforme os atendimentos. Neste caso, apresenta a evolução de um caso em específico com Síndrome de Guillain-Barré, atendido em 2021, devido a necessidade de atendimento fisioterapêutico para retorno às suas atividades de vida diária e profissional.

A experiência em poder fazer parte dessa história e ajudar a mudar o contexto final na maioria dos casos, que alegam não apresentar melhoras, vemos que a cada dia podemos estimular o nosso corpo a criar novas conexões e novas percepções. É possível afirmar que o diagnóstico não pode ser um limitador de uma vida, que é possível procurar meios para melhorá-lo ou aperfeiçoá-lo, com objetivo de proporcionar aos pacientes uma maior independência e consequentemente maior qualidade de vida dentro das suas características singulares.

\subsubsection{Ficha de Avaliação Neurofuncional}

Todo atendimento da clínica escola passa por uma avaliação complexa, capaz de avaliar o paciente de uma forma completa desde dados pessoais, determinantes de saúde, anamnese, História da moléstia atual e pregressa, descrição de exames complementares, antecedentes pessoais; exame físico direciona a avaliação para observar e analisar as capacidades e limitações que paciente possui no momento e o que é decorrente e esperado de acordo com o caso de cada paciente.

Observa-se a pele como ela se encontra, como por exemplo, normocorada, acianótica, se possui edema em alguma região do corpo; a sensibilidade se está alterada referente a dor, tato, pressão, estereognosia, proprioceptiva, cinestesia e vibratória. 
Referente ao sistema motor avaliamos o MRC escala de classificação de força muscular; Dinamometria força de preensão manual; Testes de encurtamentos de membros superiores e membros inferiores; Deformidades; Trofismomuscular; Tônus Muscular; Reflexos; se apresenta movimentos involuntários; Manobras deficitárias; Coordenação motora; Aquisições motoras o que paciente consegue realizar sem ou com apoio; Equilíbrio; Marcha; Atividades de vida diária (AVDS).

Diagnóstico fisioterapêutico de acordo com a Classificação Internacional de Funcionalidade - CIF; Objetivos e Condutas que será realizado com o paciente e quais os recursos que temos disponíveis para planejar um tratamento eficaz, e de acordo os recursos disponíveis, as técnicas aprendidas durante toda a graduação e das vivências de outros territórios e até mesmo de outras experiências.

\section{Resultados}

De acordo com o caso relatado, pode se observar melhora em membros superiores e membros inferiores, referente aos teste de força muscular através do Escore Medical Research council (MRC), que avaliou e mensurou a força muscular de grandes grupos musculares, com escore total inicial 30 pontos e final de 53 pontos após a intervenção.

Assim como, mensurado na dinamometria manual houve uma melhora na avaliação antes e após intervenção, com valores iniciais de membro superior direito de de $3 \mathrm{kgf}$, para $11 \mathrm{kgf}$, membro superior esquerdo de $4 \mathrm{kgf}$, para final $15 \mathrm{kgf}$. Nota-se que após o início do tratamento fisioterapêutico, o paciente alega que suas atividades de vida diária tem surtido melhoras em relação a executar movimentos que antes, de certa forma eram complexos e difíceis.

\section{Discussão}

As repercussões trazidas pela Síndrome de Guillain Barré estão associadas a perda súbita das capacidades funcionais, diretamente relacionada com o declínio da motricidade voluntária, causando ao indivíduo perda da autonomia. Limitações funcionais importantes que quando não tratadas geram ainda mais custos ao sistema de saúde, assim como para órgão público.

Dentre as limitações encontradas nesse paciente foram observados um perfil clássico da doença na sua fase aguda e sub aguda, o rápido diagnóstico e intervenções medicamentosas possibilitaram a regressão do quadro instalado. Porém, houveram sequelas cinético funcionais importantes que permaneceram.

A fisioterapia, se mostrou um meio eficaz por meio da individualização do tratamento e potencialização do ganho de força, com enfoque nas extremidades mais acometidas, que restringiam as atividades de autocuidado e de vida diária.

Para alcançar esses resultados, foram realizados um programa de exercícios progressivos, que visavam reequilíbrio muscular, prevenção de encurtamentos e deformidades, melhora da força muscular e retorno às capacidades funcionais desse paciente. Em concordância com outros autores, foram selecionados exercícios sequenciais com evolução gradual.

Inicialmente, foco em exercícios ativos livres ou seja sem resistência, que trabalhassem sobretudo déficit dos grupos musculares de membros superiores e inferiores. Evoluiu para exercícios resistidos, segundo estágio permitindo aumento da carga para adequação de tônus.Observou-se, melhora sobre a fraqueza, mas ainda presença de fadiga, onde iniciou terceiro estágio, com circuito de exercícios aeróbicos, associados a mimetização de atividades diárias. Foram realizados em todo tratamento exercícios de equilíbrio e propriocepção e alongamento globais.

Um trabalho executado no solo, mesclado com as propriedades da hidroterapia, que permitiam variação e desafio necessário para progresso do paciente. Com isso, podemos evidenciar a relevância das práticas terapêuticas baseadas em evidências, centradas nas necessidades individuais que trazem resolutividade dos déficit cinético funcionais, permitindo retorno do paciente a exercer sua independência e autonomia.

\section{Declaração} interesse.

Os autores declaram não ter qualquer conflito de

\section{Referências}

1- Brasil. BdS. único de Saúde - DATASUS. Estatísticas vitais. Brasília:Ministério.

2-Brasil. MS. Protocolos Clínicos e Diretrizes Terapêuticas. Brasília : Ministério da Saúde, 1ed, 2018

3- Herráez, AMM; Amorós, PA; Arteta, JM. Guillain-Barre syndrome of a patient under bortezomib treatment. Farm Hosp. 2020 Abr. 44( 2 ): 77-78.

4- Malta ,JMAS; Ramalho, WM. Aumento das internações por síndrome de Guillain-Barré no Brasil: estudo ecológico. Epidemiol. Serv. Saúde. 2020. 